\title{
Are PAMAM dendrimers safe for ocular applications? - Toxicological evaluation in ocular cells and intraocular tissues
}

Chen Qin

Wenzhou Medical University

Junmei Tang

Wenzhou Medical University

Shimin Wen

Wenzhou Medical University

SiQing Zhu

Wenzhou Medical University

Dong Liu

Wenzhou Medical University

Hao Chen

Wenzhou Medical University

Quankui Lin ( $\square$ linqk@wmu.edu.cn )

Wenzhou Medical University https://orcid.org/0000-0003-2870-6059

Research

Keywords: Biocompatibility, Dendrimer, PAMAM, Drug therapy, Ophthalmology, Biosafety

Posted Date: May 28th, 2020

DOl: https://doi.org/10.21203/rs.3.rs-30763/v1

License: (c) (i) This work is licensed under a Creative Commons Attribution 4.0 International License.

Read Full License 


\title{
Are PAMAM dendrimers safe for ocular applications?-- Toxicological evaluation in ocular cells and intraocular tissues
}

Chen Qin, Junmei Tang, Shimin Wen, SiQing Zhu, Dong Liu, Hao Chen*, Quankui Lin*

Department of Biomaterials, School of Ophthalmology \& Optometry, Eye Hospital, Wenzhou Medical University, 270 Xueyuan Road, Wenzhou 325027, China

Corresponding authors. E-mail addresses: chenhao823@mail.eye.ac.cn (H. Chen), linqk@wmu.edu.cn (Q. Lin).

\begin{abstract}
Backgrounds: The human eye is a sophisticated and sensitive sensory organ. Due to its dynamic and static barriers, efficient drug therapy for eye diseases is problematic. Polymeric delivery systems have been rapidly developed to overcome this problem, where polymeric dendrimers have received much attention for their unique structures. However, there is insufficient research on whether dendrimer nanomaterials could be used in ophthalmology. Poly (amidoamine) (PAMAM) is a kind of commercialized and extensively used dendrimer. Herein the ocular cytotoxicity and biosafety of PAMAM dendrimers were deeply evaluated by conducting in vitro and in vivo experiments on ocular systems. The effects of generation (G4.0, G5.0, and G6.0) and concentration on cell metabolism, apoptosis, and oxidative damage were carried out. Ocular irritation and intravitreal injection effects were also measured.
\end{abstract}

Results: The results showed that the cytotoxicity of PAMAM increased with increasing generation number. PAMAM at a concentration that below $50 \mu \mathrm{g} / \mathrm{mL}$ was less harmful to the ocular tissues, whereas it caused apparent damage when above 50 $\mu \mathrm{g} / \mathrm{mL}$ in the investigated situation. Moreover, singlet oxygen generation was detected in the cells after $50 \mu \mathrm{g} / \mathrm{mL}$ (and above) PAMAM treatment. The in vivo results show that there is no macroscopic structural change observed from fundus and histopathological section images, whereas it shows more functional impairment 
according to optical coherence tomography (OCT) and electroretinogram (ERG) when treated by $100 \mu \mathrm{g} / \mathrm{mL}$ PAMAM.

Conclusion: Overall, a higher concentration of PAMAM, such as above $50 \mu \mathrm{g} / \mathrm{mL}$, may cause ocular functional damage. The concentrations that are (or lower than) 50 $\mu \mathrm{g} / \mathrm{mL}$ showed good biocompatibility and biosafety in human ocular cells and tissues.

Keywords: Biocompatibility; Dendrimer; PAMAM; Drug therapy; Ophthalmology; Biosafety.

\section{Background}

The human eye is the most important and delicate optical organ in the body, providing the ability to perceive surrounding objects by converting an optical signal into an electrical one. The intricate eye can be divided into two anatomical segments: the anterior segment and the posterior segment(1). In the past decades, there has been an increase in ocular diseases that lead to blindness, which are due not only to eye trauma and infections but also to both the long-term improper use and high doses of drugs. Although the various dynamic and static barriers of the eye helps to prevent the invasion of pathogens, these protective barriers can lead to the low systemic bioavailability of useful drugs for the injured or diseased eye(2). This leads to the more frequent use of drugs with a low therapeutic index, which ultimately causes the deposition of concentrated solutions on the surface and inside of the eye, resulting in the production of toxic effects and damage to the ocular cells and tissues(3). To overcome these problems, nano-scaled drug delivery systems have been rapidly developed. Dendrimer nanomaterials, which are novel three-dimensional macromolecules with highly branched ordered structures, have been studied as carriers for drug delivery(4). Dendrimers have superior advantages owing to their highly controlled structure, responsiveness to $\mathrm{pH}$ stimuli, availability of a large number of functional groups for drug molecule attachment, and a high degree of 
control over the drug's release $(5,6)$. Although several types of dendrimers have been synthesized and investigated, Poly (amidoamine) (PAMAM) dendrimers were the most widely investigated and commercialized ones. PAMAM dendrimers are highly branched, dendritic, nano-sized polymeric composites with ethylenediamine as the nuclear structure(7). The surface of PAMAM contains plenty of amino groups, which not only provides numerous positive charges but can also be used for functional modification. Owing to its cell membrane-penetrating and high drug-loading efficiency, PAMAM has been used as a carrier of drugs for treating retinal diseases( 8 , 9), glaucoma disease(10), and corneal inflammation(11). However, there are not many published studies on whether the use of dendrimers in the ocular system is safe(12, 13). For the safe usage of PAMAM-based nanomaterials, the difference in drug sensitivity between different cells should be taken into account(14). Previous studies have demonstrated that different terminal groups of nanomaterials, such as hydroxyl $(-\mathrm{OH})$, amino $\left(-\mathrm{NH}_{2}\right)$, and carboxyl $(-\mathrm{COOH})$, have different cytotoxicities, whereas the one with amino group termination was the most toxic(15). Therefore, the primary PAMAM dendrimers terminated with amino groups are of great importance in the clinical safety investigation. As a result, in the present study, PAMAM dendrimers were evaluated for its biocompatibility to obtain guidance for its future use in ocular therapy.

\section{Results and Discussion}

Cytotoxicity is contingent on the chemistry of PAMAM dendrimers. The contact between a surface cationic charge of PAMAM dendrimers and negatively charged cell membranes is the main reason for toxicity. Among all common terminal groups, amine provides the most surface cationic charge of PAMAM dendrimers, which means PAMAM is more representative in the assessment of biocompatibility. For this reason, we mainly chose PAMAM to evaluate the ocular cytotoxicity. As shown in Table 1, the average size of PAMAM G4.0, G5.0, and G6.0 was about $4.52 \pm 1.05 \mathrm{~nm}$, $14.7 \pm 2.03 \mathrm{~nm}$, and $21.2 \pm 3.10 \mathrm{~nm}$, respectively. All three generation PAMAM had a cationic charge surface. 


\section{Table 1}

Summary of size and zeta potential of PAMAM dendrimers.

\begin{tabular}{lcc}
\hline Dendrimer Type & Size $(\mathrm{nm})$ & Zeta $(\mathrm{mv})$ \\
\hline PAMAM G4.0 & $4.52 \pm 1.05$ & $4.38 \pm 0.28$ \\
PAMAM G5.0 & $14.7 \pm 2.03$ & $10.35 \pm 1.08$ \\
PAMAM G6.0 & $21.2 \pm 3.10$ & $18.33 \pm 0.50$ \\
\hline
\end{tabular}

Results indicate the average mean $\pm S D, n=3$.

\section{In vitro biocompatibility evaluation}

The biocompatibility of different PAMAM solutions was tested on HCECs, HLECs, and RPEs, which correspond to the ocular surface, anterior segment, and the posterior segment, respectively. The PAMAM G5.0 solution had no significant effect on cell growth when the concentration was lower than $50 \mu \mathrm{g} / \mathrm{mL}$ (Fig. 1). By contrast, when the concentration was $100 \mu \mathrm{g} / \mathrm{mL}$, less live HLECs were detected and many cracked cells appeared at the same time, indicating that a high concentration of PAMAM G5.0 had a significant impact on cell activity (Fig. 1D).
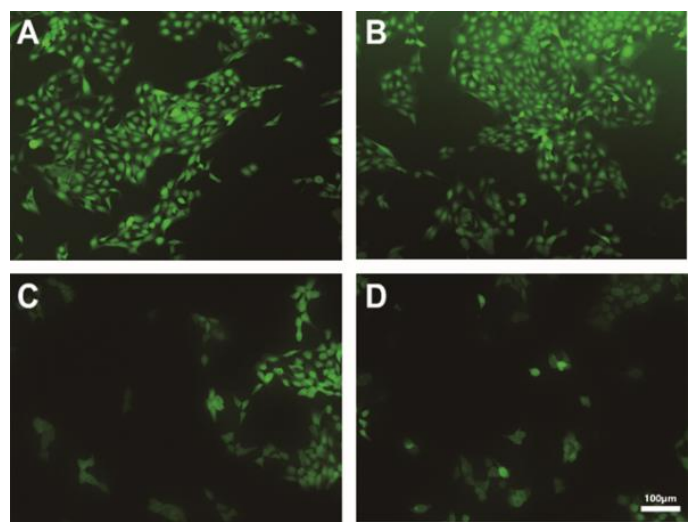

Fig.1.Fluorescence images of HLEC cells incubated with PMAMA-NH ${ }_{2}$ G5.0 aqueous solution with concentrations of (A) $5 \mu \mathrm{g} / \mathrm{mL}$, (B) $25 \mu \mathrm{g} / \mathrm{mL}$, (C) $50 \mu \mathrm{g} / \mathrm{mL}$, and (D) $100 \mu \mathrm{g} / \mathrm{mL}$ overnight after FDA staining for 15 mins.

According to previous studies on different animals and mammalian cells, the size 
and charge of PAMAM nanomaterials are highly relevant to their toxicity(16-18). For further quantification of the cytotoxicity, different areas were chosen for cell counting by ImageJ software. There was an obvious decrease in cell number with the $50 \mu \mathrm{g} / \mathrm{mL}$ PAMAM G5.0 solution (Fig. 2A). For accurate quantification of the biocompatibility of PAMAM, which has been used more as a drug carrier in the therapeutic field $(19,20)$, its cytotoxicity at the concentration range of $1-100 \mu \mathrm{g} / \mathrm{mL}$ in three different ocular cell lines was evaluated using the CCK-8 method. As shown in Fig. 2, the cytotoxic effects of commercial PAMAM were dependent on its concentration and generation number. All three PAMAM generations showed evident cytotoxicity toward the HLECs, as indicated by the low cell viabilities of below $65 \%$ at PAMAM G4.0 concentrations of over $75 \mu \mathrm{g} / \mathrm{mL}$, below $60 \%$ at PAMAM G5.0 concentrations of over $50 \mu \mathrm{g} / \mathrm{mL}$, and below $50 \%$ at PAMAM G6.0 concentrations of over $50 \mu \mathrm{g} / \mathrm{mL}$ (Fig. 2B). The high number of positive charges of the dense terminal amines of PAMAM interact with the negatively charged lipid bilayers of the cell membrane, which eventually leads to membrane disruption $(21,22)$. At the same time, PAMAM showed a time-dependent cytotoxic effect. After $24 \mathrm{~h}$ of incubation, there was no significant difference in cell viability at the G4.0 concentrations of 5-100 $\mu \mathrm{g} / \mathrm{mL}$ because of the low toxicity of this particular PAMAM dendrimer, indicating that $50 \mu \mathrm{g} / \mathrm{mL}$ was not the determining concentration for the cytotoxicity effect. However, after 48 and $72 \mathrm{~h}$ incubation with PAMAM G4.0, a significant decrease in its cytotoxicity was noted when the HCECs were exposed to the highest concentration of $100 \mu \mathrm{g} / \mathrm{mL}$, the decrease was approximately $40 \%$ (Fig. 2C)(23). Remarkably, the different types of cells had different resistance to PAMAM, in the order of HCECs > HLECs > RPEs (Fig. 2D). This is probably because the cornea is the outer barrier of the eye, and the retina is a sensitive tissue for photoelectric conversion. 

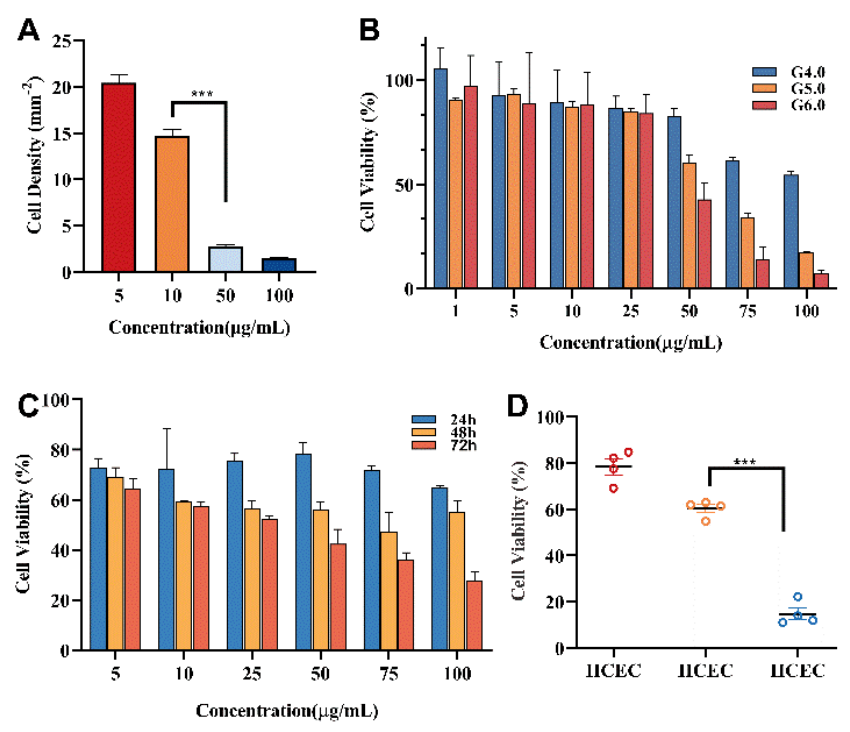

Fig. 2. Concentration and generation dependent cell viability of PAMAM incubated with HCECs, HLECs, and RPEs. (A)HLECs density after PAMAM G5.0 treatment overnight. (B) The cell viability of different generations and concentrations of PAMAM incubated with HLECs. (C) Time-dependent cell viability of PAMAM G4.0 incubated with HCECs. (D) The cell viability of PAMAM G5.0 in different ocular cells when the concentration is $50 \mu \mathrm{g} / \mathrm{mL}$.

The apoptotic effect was detected by Hoechst 33342 staining, which is a method used to distinguish apoptotic cells from healthy cells (Fig. 3). Apoptotic cells usually exhibit condensed DNA or fragmented nuclei that show up as bright blue fluorescence, which necrotic and healthy cells do not have(24). Unlike the control cells (Fig. 3A), RPEs incubated with 50 and $100 \mu \mathrm{g} / \mathrm{mL}$ of PAMAM G5.0 showed enhanced chromatin fluorescence from Hoechst 33342, which made up the majority of the cell nucleus (Fig. 3C and D). The results revealed that PAMAM G5.0 at over $50 \mu \mathrm{g} / \mathrm{mL}$ induced DNA condensation prominently.

The cytotoxicity of nanoparticles has been proven to have its origins in the oxidative stress induced by free radical formation(25). PAMAM G5.0 was chosen to assess its capability of inducing ROS generation, where DCFH-DA was used as the indicator molecule that could be rapidly oxidized to dichlorofluorescein (a detectable 
fluorescent species) in the presence of $\operatorname{ROS}(26)$. As shown in Fig. 4, PAMAM G5.0 could generate singlet oxygen. Compared with the fluorescence intensity of the positive control cells (Fig. 4A), the fluorescence intensity of PAMAM G5.0-treated cells remained at a low level, where that at the lowest concentration of $5 \mu \mathrm{g} / \mathrm{mL}$ seemed brighter than the intensity at the other concentrations. Considering the obvious toxicity of the cationic PAMAM of high concentrations as well as a prolonged (24h) irritation, the number of residual lived cells was low. According to Fig. 2C, the RPEs were more sensitive to the toxicity of cationic PAMAM. These caused a brighter fluorescence intensity at the lowest concentration of $5 \mu \mathrm{g} / \mathrm{mL}$ than that at the other concentrations. Besides, the ROS level was found to be PAMAM concentration, generation number, and time-dependent(27).
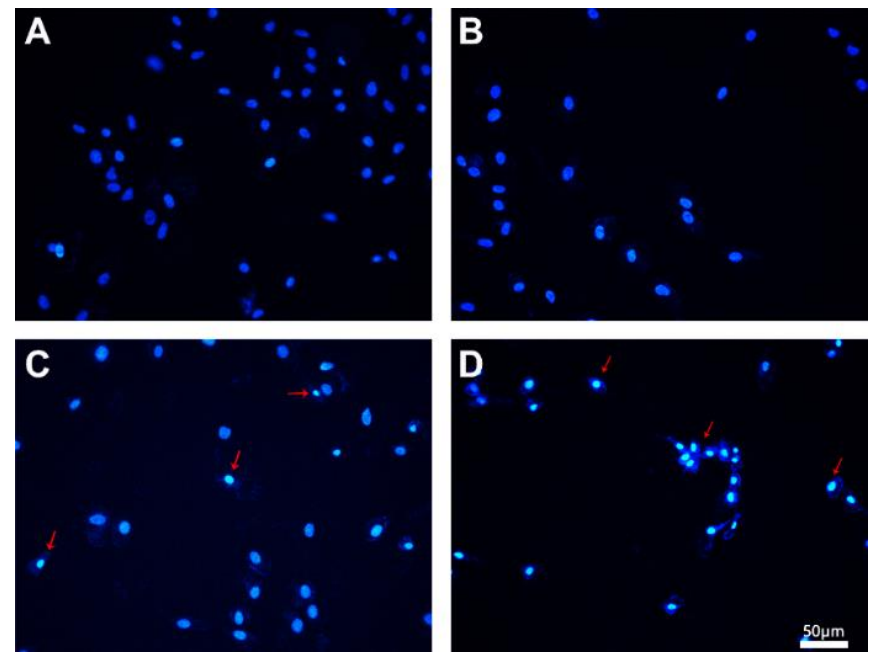

Fig. 3. Hoechst 33342 stained cell nuclear morphology of RPEs in different concentrations of PAMAM G5.0 solution treatment after 24 hours incubation. PAMAM G5.0 solution: (A) PBS as a control; (B) $25 \mu \mathrm{g} / \mathrm{mL}$; (C) $50 \mu \mathrm{g} / \mathrm{mL}$; and (D) $100 \mu \mathrm{g} / \mathrm{mL}$. 

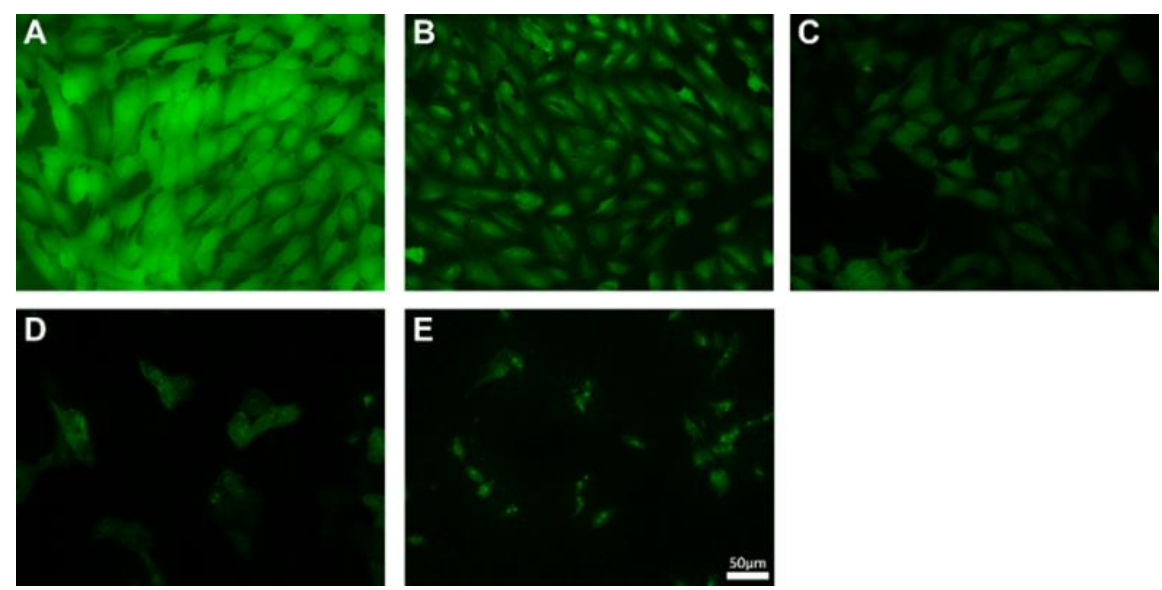

Fig. 4. Singlet oxygen generation and enhanced in vitro cytotoxicity. Fluorescence images of RPEs incubated with PAMAM G5.0 solution (A) Rosup solution as positive control, (B) $5 \mu \mathrm{g} / \mathrm{mL}$, (C) $25 \mu \mathrm{g} / \mathrm{mL}$, (D) $50 \mu \mathrm{g} / \mathrm{mL}$, (E) $100 \mu \mathrm{g} / \mathrm{mL}$.

\section{In vivo biocompatibility evaluation}

The in vivo environment is more complicated than the in vitro one. To further determine the feasibility of the biomedical application of the dendrimers in the ocular system, PAMAM G5.0 was tested for its ability to cause acute ocular irritation at 50 and $100 \mu \mathrm{g} / \mathrm{mL}$. As shown in Fig. 5, after fluorescein disodium salt staining, no obvious damage on the corneal surface could be seen at different times. Because the eye itself has a protective barrier and tear scour alternate behavior, the slit lamp results proved that there was no difference between the high and low concentrations of PAMAM G5.0 in terms of non-damaging effects, which was in accord with the fact that HCECs were more resistant to adverse environments.

The PAMAM solutions were further intravitreal injection into the vitreous body antrum of the right eye in rabbits for evaluation of the in vivo biosafety. The in vivo effect of PAMAM on the fundus tissue morphology and visual function were investigated. As shown in Fig. 6, the fundus images showed that there was no noticeable difference with or without PAMAM injection in both investigated concentrations (50 and $100 \mu \mathrm{g} / \mathrm{mL}$ ). Much blood capillary and optic disc were shown in the untreated opposite eyes' fundus (Fig. 6 A2 and B2). Compared with the untreated opposite eye, no abnormality of fundus blood capillary and optic disc was 
found after $50 \mu \mathrm{g} / \mathrm{mL}$ PAMAM injections in the investigated conditions (Fig. $6 \mathrm{A1}$ and B1). No difference was found between the concentrations of 50 and $100 \mu \mathrm{g} / \mathrm{mL}$ (Fig. 6 A1 and A2).

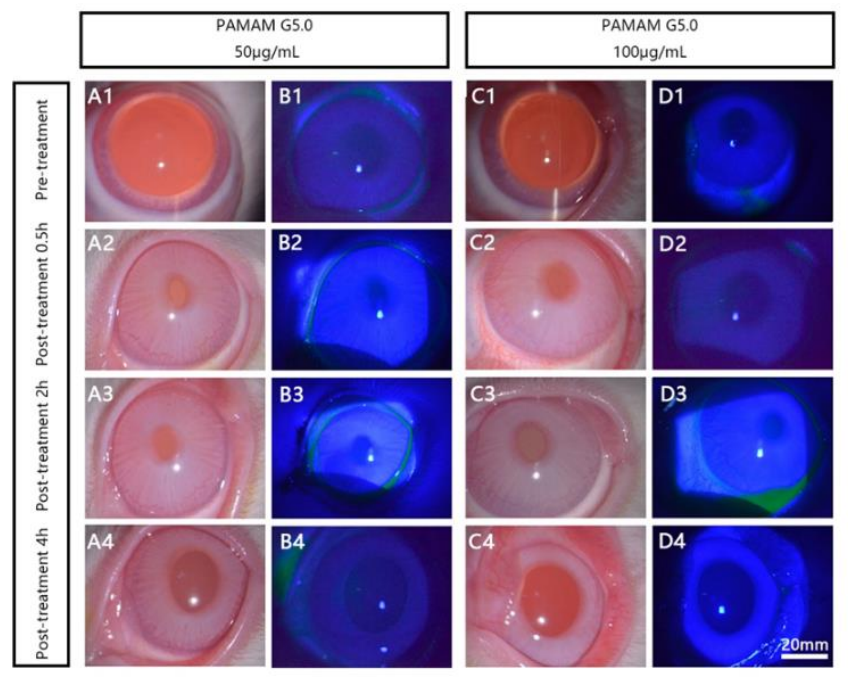

Fig. 5. Representative slit-lamp photographs (with or without fluorescein disodium staining) of the rabbit eyes irritated by PAMAM G5.0 at the concentration of 50 $\mu \mathrm{g} / \mathrm{mL}$ (A1-A4, B1-B4) and $100 \mu \mathrm{g} / \mathrm{mL}$ (C1-C4, D1-D4) pre-treatment and post-treatment $0.5 \mathrm{~h}, 2 \mathrm{~h}, 4 \mathrm{~h}$.
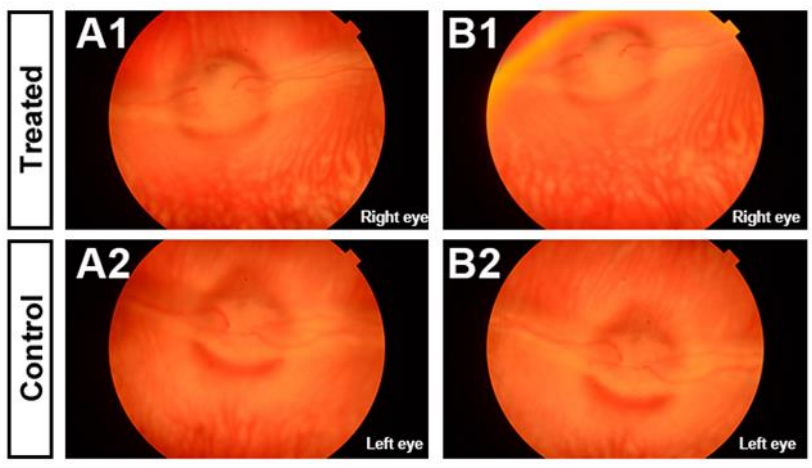

Fig. 6. The fundus images of the rabbit eyes after $20 \mu \mathrm{L}$ PAMAM G5.0 intravitreal injection for 7 days at the concentration of $50 \mu \mathrm{g} / \mathrm{mL}$ (A1) and $100 \mu \mathrm{g} / \mathrm{mL}$ (B1). The untreated opposite eyes were severed as the negative control (A2 and B2).

The in vivo effects of PAMAM with different concentrations on the ocular tissues, such as cornea and retina, were also investigated by the histological paraffin sections observation (Fig. 7). The cornea has a characteristic five-layered structure consisting of the epithelium, Bowman's membrane, stroma, Descemet's membrane, and 
endothelium(28). The corneal tissue from rabbits treated with dendrimer had a clear organizational structure (Fig. 7 A and B)(29). Similar results were found in the retinal tissues (Fig. 7 C and D).
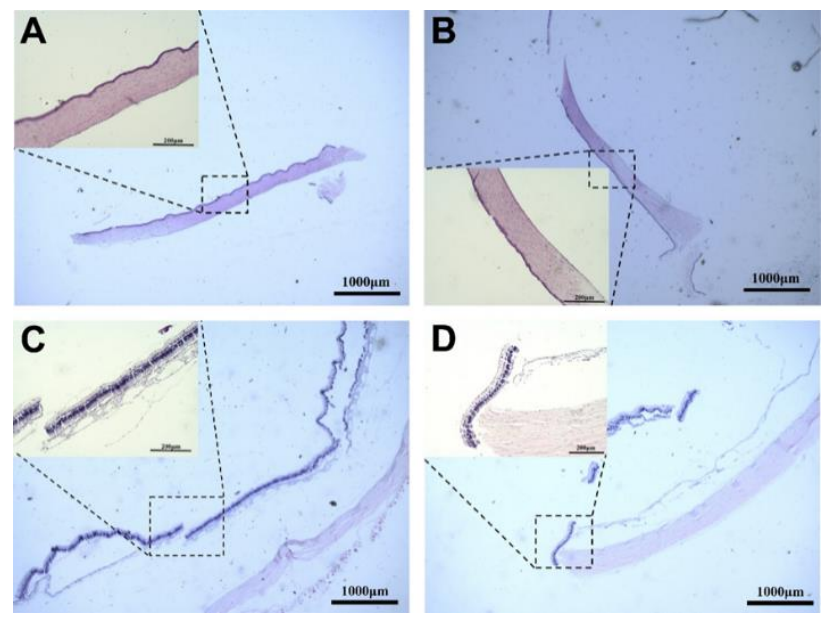

Fig. 7. Light photomicrographs of histological section images of the cornea (A, B) and retina (C, D) after $50 \mu \mathrm{g} / \mathrm{mL}$ (A and C) and 100 $\mu \mathrm{g} / \mathrm{mL}$ (B and D) PAMAM G5.0 intravitreal injection for 7 days.

The structure of the retina is complete and the boundary is clear after PAMAM treatment, no matter at 50 or $100 \mu \mathrm{g} / \mathrm{mL}$. The OCT was conducted to obtain a more accurate evaluation of the intraocular biocompatibility of the nanomaterials (Fig. 8). OCT is a cross-sectional, micrometer-scale imaging modality, which has been widely applied in ophthalmology clinics. The OCT images showed that there was no significant toxicity at both concentrations of 50 and $100 \mu \mathrm{g} / \mathrm{mL}$ in the 3 days postoperatively, compared with preoperative eyes (Fig. 8 A1, A2, and B1, B2). When the postoperative time increased to 7 days, however, the results came out differently. There were a large number of hyperintense spots visualized in the vitreous cavity when exposure by the PAMAM $100 \mu \mathrm{g} / \mathrm{mL}$ injection at 7 days postoperatively (Fig. 8 B3). By contrast, the vitreous cavity kept clear when the injected PAMAM concentration is $50 \mu \mathrm{g} / \mathrm{mL}$. These results indicated that although there was no obvious morphology change detected in the ocular tissues, the high concentration (such as 100 $\mu \mathrm{g} / \mathrm{mL}$ ) of PAMAM injection may have some unknown effect on the retina. As a result, the visual function of the retina was evaluated to confirm the in vivo biosafety 
of the PAMAM at the 50 and $100 \mu \mathrm{g} / \mathrm{mL}$.

The visual function of the retina was measured by ERG. As shown in Fig. 9, the ERG results showed that they were no obvious difference in the PAMAM treatment by 50 $\mu \mathrm{g} / \mathrm{mL}$ postoperatively 7 days, no matter in the light adaptation (Fig. 9 A-iii and -iv) or dark adaptation (Fig. 9 A-i and ii), which means that the PAMAM injection does not influence the cone and rod functions in the retina $(30,31)$. There was also no obvious difference in the light adaptation after the PAMAM treatment with 100 $\mu \mathrm{g} / \mathrm{mL}$ postoperatively one-week (Fig. 9 B-iii and -iv). However, although 0.01 ERG of the dark adaptation results showed no significant difference in the treated or untreated eyes (Fig. 9 A-i), the 3.0 ERG results of the dark adaptation revealed that a significant change in the a-wave was found when the eye was exposure to $100 \mu \mathrm{g} / \mathrm{mL}$ PAMAM after 1 week (Fig. 9 B-ii). The amplitude of a-wave in the untreated eye (Fig. 9, ii-left eye) was $8.5 \mu \mathrm{V}$, whereas the amplitude of a-wave in $100 \mu \mathrm{g} / \mathrm{mL}$ PAMAM treated right eye was $1.3 \mu \mathrm{V}$. A significant amplitude reduction of the a-wave was found in this situation, which meant that there was some abnormality in cone function when the eye was injected with $100 \mu \mathrm{g} / \mathrm{mL}$ PAMAM. These results tell that a higher concentration of PAMAM, such as above $50 \mu \mathrm{g} / \mathrm{mL}$, may cause ocular functional damage to some extent. The concentrations that are (or lower than) $50 \mu \mathrm{g} / \mathrm{mL}$ showed good biocompatibility and biosafety in human ocular cells and tissues.
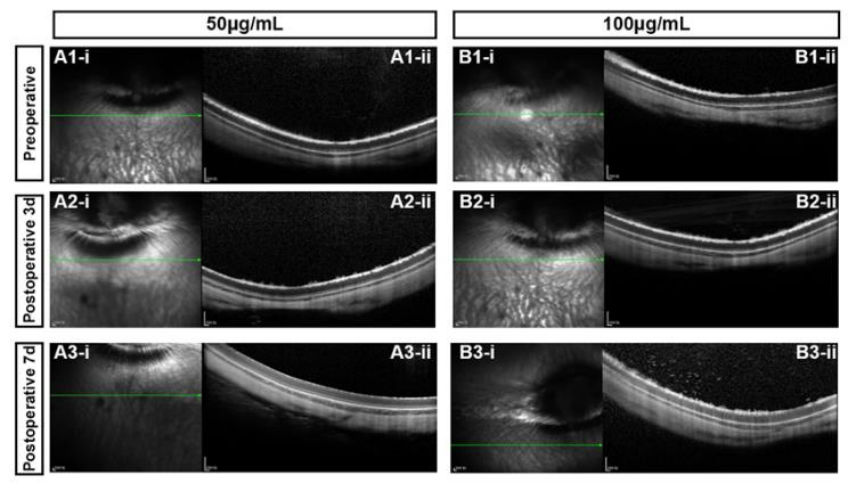

Fig. 8. Pre (A1, B1) and postoperative 3 days (A2, B2), 7 days (A3, B3) OCT images of the fundus (A-i, B-i) and its cross-section view (A-ii, B-ii) after $50 \mu \mathrm{g} / \mathrm{mL}$ (A) and $100 \mu \mathrm{g} / \mathrm{mL}$ (B) PAMAM G5.0 intravitreal injection for 1 week. 


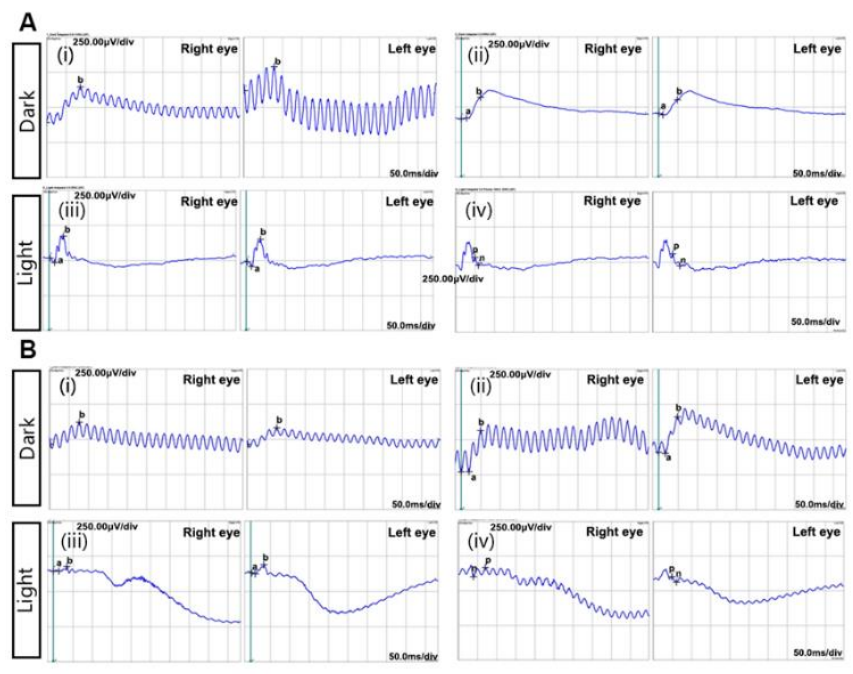

Fig. 9. The ERG results of the rabbit eyes after $50 \mu \mathrm{g} / \mathrm{mL}$ (A-right eye) and 100 $\mu \mathrm{g} / \mathrm{mL}$ (B-right eye) PAMAM G5.0 intravitreal injection for 7 days. The untreated opposite eyes were severed as the negative control (A-left eye, B-left eye). ERG MODE: Dark Adapted 0.01 ERG (i), Dark Adapted 3.0 ERG (ii), Light Adapted 3.0 ERG (iii), and Light Adapted 3.0 Flicker 30Hz ERG (iv).

\section{Conclusions}

High concentrations of PAMAM, a novel nano-drug carrier, can trigger both apoptosis and singlet oxygen generation in ocular cells, such as HCECs, HLECs, and RPEs. Moreover, its cytotoxicity depends on its concentration, generation number, and time. Although it does not have highly strict boundaries to distinguish its degree of safety or its harmful dose, the in vitro results above indicate that the safety limit for PAMAM dendrimers of over generation 5.0 maybe $50 \mu \mathrm{g} / \mathrm{mL}$, whereas that for dendrimers below generation 4.0 maybe $75 \mu \mathrm{g} / \mathrm{mL}$. Although a more exact quantification in ocular cells is still needed, the present finding of the intraocular biocompatibility of the PAMAM at the concentration of $50 \mu \mathrm{g} / \mathrm{mL}$ nonetheless provides meaningful guidance toward its future use in ocular-related medical therapy.

\section{Methods}

\section{Reagents and Materials}

Fluorescein diacetate (FDA) was purchased from Sigma-Aldrich (Shanghai, China). The Hoechst 33342 stain, Cell Counting Kit-8 (CCK-8), lactate dehydrogenase release assay kit, 2',7'-dichlorodihydrofluorescein diacetate (DCFH-DA), and reactive 
oxygen species (ROS) assay kit were purchased from Beyotime Biotechnology Co. (Shanghai, China). Hank's balanced salt solution (HBSS) was purchased from Dalian Meilun Biotechnology (Dalian, China). Fetal bovine serum (FBS), trypsin-ethylenediaminetetraacetic acid solution, penicillin-streptomycin solution, and Dulbecco's modified Eagle's medium/nutrient mixture F-12 (DMEM/F-12; 1:1 ratio) were purchased from Thermo Fisher Scientific (Carlsbad, CA, USA). Phosphate-buffered saline (PBS) was purchased from Boster Biological Technology (Pleasanton, CA, USA). The PAMAM G4.0 dendrimer, PAMAM G5.0 dendrimer, and PAMAM G6.0 dendrimer (generation 4.0, 5.0, and 6.0 solutions, respectively, all with an ethylenediamine core) were purchased from Sigma-Aldrich (Shanghai, China). All chemicals were of analytical grade and stored and used according to the manufacturers' instructions.

\section{Cell culture}

Human lens epithelial cells (HLECs) and retinal pigment epithelium cells (RPEs) were cultured in DMEM/F-12, whereas human corneal epithelial cells (HCECs) were cultured in DMEM/F-12 containing L-glutamine. Both culture media contained 10\% FBS and $1 \%$ penicillin-streptomycin, and all cells were incubated at $37^{\circ} \mathrm{C}$ in $5 \%$ CO2-containing humidified atmosphere.

\section{Animals}

Seven to nine-week-old male New Zealand White rabbits were obtained from Wenzhou Medical University Animal Laboratory. The rabbits' experiment protocol was approved by the Laboratory Animal Ethics Committee of Wenzhou Medical University. All in vivo experiments were performed consistent with the Animal Experimentation Guidelines of Wenzhou Medical University.

\section{Particle size and zeta potential}

The particle size and zeta potential of PAMAM were measured by dynamic light scattering (DLS). The different generations PAMAM nano-particle was dissolved in Milli-Q water at $25^{\circ} \mathrm{C}$ at a concentration of $500 \mu \mathrm{g} / \mathrm{mL}$ and well mixed by vortex finder for 5 mins, respectively. The values were recorded in triplicate for each sample 
to gain the average particle size and zeta potential.

\section{In Vitro Cell viability assay}

\section{Cell Activity assay}

HLECs in the logarithmic growth phase were seeded into 96-well plates and cultured at $37^{\circ} \mathrm{C}$ under $5 \% \mathrm{CO}$. Then, $20 \mu \mathrm{L}$ of different concentrations of PAMAM G5.0 (5, 10,50 , and $100 \mu \mathrm{g} / \mathrm{mL}$ ) was added to the respective wells of the plate. After $24 \mathrm{~h}$ incubation, the cells were stained with FDA (diluted 1000 times) for $15 \mathrm{~min}$. Then, after 3 rapid washes with PBS, the green fluorescence of the live cells was monitored by fluorescence microscopy.

\section{Cytotoxicity Assay}

Cytotoxicity was evaluated by CCK-8 test. HECEs, RPEs, and HLECs were precultured in 96-well plates at the density of $5 \times 103$ cells every well. To compare the cytotoxicity effect of different PAMAM dendrimer nanomaterials, the cells were treated with PAMAM dendrimer of different concentrations and algebra, and the control cells were likewise treated with PBS of the same volume. After 24, 48, and 72 $\mathrm{h}$ of incubation, the culture medium was replaced with $100 \mu \mathrm{L}$ of fresh culture medium containing a $10 \%$ volume of CCK- 8 solution and the plates were incubated for approximately $2 \mathrm{~h}$. The optical density (OD) values were detected with a fluorescence microplate reader. The cell viability was calculated as follows: Cell viability $(\%)=($ ODdisposed - ODblank $) /($ ODcontrol - ODblank $)$.

\section{Apoptosis Detection}

HLECs $(1 \times 104$ cells/well in a 96-well plate $)$ were treated with different concentrations of PAMAM G5.0 $(5,25,50$, or $100 \mu \mathrm{g} / \mathrm{mL})$ and incubated at $37^{\circ} \mathrm{C} 5 \%$ CO2 overnight. Thereafter, $100 \mu \mathrm{L}$ of Hoechst 33342 stain was added to each well of the plate, and incubation was carried out at room temperature in the dark for $5 \mathrm{~min}$. Then, after washing 3 times with PBS ( 3 min per wash), the blue fluorescence was detected by fluorescence microscopy.

\section{Singlet Oxygen Generation}


PAMAM G5.0 was chosen to assess its singlet oxygen generation capability, as detected using a commercial assay kit with the DCFH-DA fluorescent probe. In brief, different concentrations of the PAMAM G5.0 solution and PBS were mixed with 10 $\mu \mathrm{M}$ DCFH-DA, respectively. The fluorescence of the mixed solutions was detected with a multifunctional enzyme spectrometer and fluorescence microscope.

\section{In Vivo tissue assay}

\section{Acute ocular irritation assessment}

PAMAM solutions of different concentrations (50 and $100 \mu \mathrm{g} / \mathrm{mL}$ ) were dripped onto the ocular surface of Japanese white rabbits, where 3 drops of each concentration were applied, respectively. Then, the status of the eyes before and 0.5, 2, and $4 \mathrm{~h}$ after the procedure was detected using a slit lamp following fluorescein disodium salt staining.

\section{Intravitreal injection}

All instruments were sterilized at high temperature and humidity. The anesthetized rabbits were dilated the pupil with atropine, then Iodine was used to sterilize and topical anesthesia is performed with propantheline. After that $20 \mu \mathrm{L}$ of the 50 and 100 $\mu \mathrm{g} / \mathrm{mL}$ PAMAM solutions were respectively injected into the right eye of rabbits intravitreally at the temporal margin of the cornea $4 \mathrm{~mm}$ with a $30 \mathrm{G}$ syringe. The fundus retinal structures of the eyes were determined by optical coherence tomography (OCT) before and postoperative 3 days, and 1 week after the injection procedure. The retinal morphologies and visual functions were observed by fundus camera examination and electroretinogram (ERG) at postoperative 1 week respectively. Then the rabbits were euthanized by air embolism after excessive anesthesia. The eyeballs were collected and the histological paraffin sections of cornea and retina were prepared and stained by hematoxylin-eosin staining according to the standard procedure $(32,33)$.

\section{Statistical analysis}

The statistical analysis and one-way analysis of variance were performed with GraphPad Prism (version 8.0). The significance level was set at $\mathrm{p}<0.05$. Differences with $\mathrm{p}>0.05$ were considered statistically insignificant, those with $\mathrm{p}<0.05(*)$ were 
considered significant, and those with $\mathrm{p}<0.01(* *)$ and $\mathrm{p}<0.001(* * *)$ were considered very significant.

\section{List of abbreviations}

PAMAM: Poly (amidoamine); generation 4.0, 5.0, 6.0: G4.0, G5.0, and G6.0;

DCFH-DA: 2',7'-Dichlorodihydrofluorescein diacetate;

ROS: Reactive oxygen species;

HBSS: Hank's balanced salt solution;

FBS: Fetal bovine serum;

DMEM/F-12: Dulbecco's modified Eagle's medium/nutrient mixture F-12;

PBS: Phosphate-buffered saline;

HLECs: Human lens epithelial cells;

RPEs : Retinal pigment epithelium cells;

HCECs: Human corneal epithelial cells;

DLS: Dynamic light scattering;

OCT: Optical coherence tomography;

ERG: Electroretinogram;

FDA: Fluorescein diacetate.

\section{Acknowledgments}

The authors would like to take this chance to thank all institutions for their technical supports.

\section{Authors' contributions}

CQ conception and design, collection and assembly of data, data analysis and interpretation, manuscript writing; JMT, SMW, SQZ and DL: collection and/or assembly of data, data analysis and interpretation; HC: conception and design, data analysis and interpretation, financial support, manuscript writing; QKL: conception and design, data analysis and interpretation, financial support, manuscript writing, final approval of manuscript. All authors read and approved the final manuscript. 


\section{Funding}

This project is part of the National Key R\&D Program (2017YFC1104602), National

Natural Science Foundation of China $(31570959,81771984)$, and the Top-notch Youth Talent of "Ten Thousand Talents Program" of Zhejiang Province.

\section{Ethics approval and consent to participate}

The experiment was approved by the Laboratory Animal Ethics Committee of Wenzhou Medical University.

\section{Availability of data and materials}

All data generated or analyzed during this study are included in this published article.

\section{Consent for publication}

All authors agree on publication.

\section{Competing interests}

The authors declare that they have no competing interests.

\section{Reference}

1. Janagam DR, Wu L, Lowe TL. Nanoparticles for drug delivery to the anterior segment of the eye. Adv Drug Deliv Rev. 2017;122:31-64.

2. Gote V, Sikder S, Sicotte J, Pal D. Ocular Drug Delivery: Present Innovations and Future Challenges. J Pharmacol Exp Ther. 2019;370:602-24.

3. Yadav KS, Rajpurohit R, Sharma S. Glaucoma: Current treatment and impact of advanced drug delivery systems. Life Sci. 2019;221:362-76.

4. Li Y, Zeng X, Wang S, Sun Y, Wang Z, Fan J, et al. Inhibition of autophagy protects against PAMAM dendrimers-induced hepatotoxicity. Nanotoxicology. 2015;9(3):344-55.

5. Igartua DE, Martinez CS, Temprana CF, Alonso SDV, Prieto MJ. PAMAM dendrimers as a carbamazepine delivery system for neurodegenerative diseases: A biophysical and nanotoxicological characterization. Int J Pharmaceut. 2018;544(1):191-202.

6. Qiu X, Cao K, Lin T, Chen W, Yuan A, Wu J, et al. Drug delivery system based on dendritic nanoparticles for enhancement of intravesical instillation. Int J Nanomed. 2017;12:7365-74.

7. Xie H, Li L, Sun Y, Wang Y, Gao S, Tian Y, et al. An Available Strategy for Nasal Brain Transport of Nanocomposite Based on PAMAM Dendrimers via In Situ Gel. Nanomaterials (Basel). 2019;9(2).

8. Wong CW, Wong TT. Posterior segment drug delivery for the treatment of exudative age-related 
macular degeneration and diabetic macular oedema. Brit J Ophthalmol. 2019;103:1356-60.

9. Jiang S, Franco YL, Zhou Y, Chen J. Nanotechnology in retinal drug delivery. Int J Ophthalmol. 2018;11(6):1038-44.

10. Lancina MG, 3rd, Wang J, Williamson GS, Yang H. DenTimol as A Dendrimeric Timolol Analogue for Glaucoma Therapy: Synthesis and Preliminary Efficacy and Safety Assessment. Mol Pharmaceut. 2018;15(7):2883-9.

11. Soiberman U, Kambhampati SP, Wu T, Mishra MK, Oh Y, Sharma R, et al. Subconjunctival injectable dendrimer-dexamethasone gel for the treatment of corneal inflammation. Biomaterials. 2017;125:38-53.

12. Lai S, Wei Y, Wu Q, Zhou K, Liu T, Zhang Y, et al. Liposomes for effective drug delivery to the ocular posterior chamber. J Nanobiotechnol. 2019;17(1):64.

13. Wu LP, Ficker M, Christensen JB, Trohopoulos PN, Moghimi SM. Dendrimers in Medicine: Therapeutic Concepts and Pharmaceutical Challenges. Bioconjugate Chem. 2015;26(7):1198-211.

14. Perreault F, Melegari SP, Fuzinatto CF, Bogdan N, Morin M, Popovic R, et al. Toxicity of PAMAM-coated gold nanoparticles in different unicellular models. Environ Toxicol. 2014;29(3):328-36.

15. Shen C, Han Y, Wang B, Tang J, Chen H, Lin Q. Ocular biocompatibility evaluation of POSS nanomaterials for biomedical material applications. RSC Adv. 2015;5(66):53782-8.

16. Naha PC, Mukherjee SP, Byrne HJ. Toxicology of Engineered Nanoparticles: Focus on Poly(amidoamine) Dendrimers. Int J Env Res Pub He 2018;15(2).

17. Mukherjee SP, Lyng FM, Garcia A, Davoren M, Byrne HJ. Mechanistic studies of in vitro cytotoxicity of poly(amidoamine) dendrimers in mammalian cells. Toxicol Appl Pharm. 2010;248(3):259-68.

18. Lee JH, Cha KE, Kim MS, Hong HW, Chung DJ, Ryu G, et al. Nanosized polyamidoamine (PAMAM) dendrimer-induced apoptosis mediated by mitochondrial dysfunction. Toxicol Lett. 2009;190(2):202-7.

19. Morris CJ, Aljayyoussi G, Mansour O, Griffiths P, Gumbleton M. Endocytic Uptake, Transport and Macromolecular Interactions of Anionic PAMAM Dendrimers within Lung Tissue. Pharm Res. 2017;34(12):2517-31.

20. Kamaleddin MA. Nano-ophthalmology: Applications and considerations. Nanomedicine. 2017;13(4):1459-72.

21. Wang G, Fu L, Walker A, Chen X, Lovejoy DB, Hao M, et al. Label-Free Fluorescent Poly(amidoamine) Dendrimer for Traceable and Controlled Drug Delivery. Biomacromolecules. 2019;20(5):2148-58.

22. Lombardo D, Calandra P, Bellocco E, Lagana G, Barreca D, Magazu S, et al. Effect of anionic and cationic polyamidoamine (PAMAM) dendrimers on a model lipid membrane. BBA-Biomembranes. 2016;1858(11):2769-77.

23. Lee CC, MacKay JA, Frechet JM, Szoka FC. Designing dendrimers for biological applications. Nat Biotechnol. 2005;23(12):1517-26.

24. Wang T, Hu J, Luo H, Li H, Zhou J, Zhou L, et al. Photosensitizer and Autophagy Promoter Coloaded ROS-Responsive Dendrimer-Assembled Carrier for Synergistic Enhancement of Tumor Growth Suppression. Small. 2018;14(38):e1802337.

25. $\mathrm{Xu} \mathrm{Q}$, Wang C-H, Wayne Pack DJCPD. Polymeric Carriers for Gene Delivery: Chitosan and Poly(amidoamine) Dendrimers. Curr Pharm Design. 2010;16(21):2350-68. 
26. Liu L-H, Qiu W-X, Li B, Zhang C, Sun L-F, Wan S-S, et al. A Red Light Activatable Multifunctional Prodrug for Image-Guided Photodynamic Therapy and Cascaded Chemotherapy. Adv Funct Mater. 2016;26(34):6257-69.

27. Naha PC, Davoren M, Lyng FM, Byrne HJ. Reactive oxygen species (ROS) induced cytokine production and cytotoxicity of PAMAM dendrimers in J774A.1 cells. Toxicol Appl Pharm. 2010;246(1-2):91-9.

28. Lin QK, Tang JM, Han YM, Xu X, Hao XJ, Chen H. Hydrophilic modification of intraocular lens via surface initiated reversible addition-fragmentation chain transfer polymerization for reduced posterior capsular opacification. Colloid Surface B. 2017;151:271-9.

29. Han YM, Xu X, Tang JM, Shen CH, Lin QK, Chen H. Bottom-up fabrication of zwitterionic polymer brush on intraocular lens for improved biocompatibility. Int J Nanomed. 2017;12:127-35.

30. Ahn SM, Ahn J, Cha S, Yun C, Park TK, Kim YJ, et al. The effects of intravitreal sodium iodate injection on retinal degeneration following vitrectomy in rabbits. Sci Rep. 2019;9(1):15696.

31. Halupka KJ, Abbott CJ, Wong YT, Cloherty SL, Grayden DB, Burkitt AN, et al. Neural Responses to Multielectrode Stimulation of Healthy and Degenerate Retina. Invest Ophthalmol Vis Sci. 2017;58(9):3770-84.

32. Han Y, Tang J, Xia J, Wang R, Qin C, Liu S, et al. Anti-adhesive and antiproliferative synergistic surface modification of intraocular lens for reduced posterior capsular opacification. Int J Nanomed. 2019;14:9047-61.

33. Lin $\mathrm{QK}, \mathrm{Xu} \mathrm{X}$, Wang $\mathrm{Y}$, Wang B, Chen H. Antiadhesive and antibacterial polysaccharide multilayer as IOL coating for prevention of postoperative infectious endophthalmitis. Int J Polym Mater. 2017;66(2):97-104. 
Figures
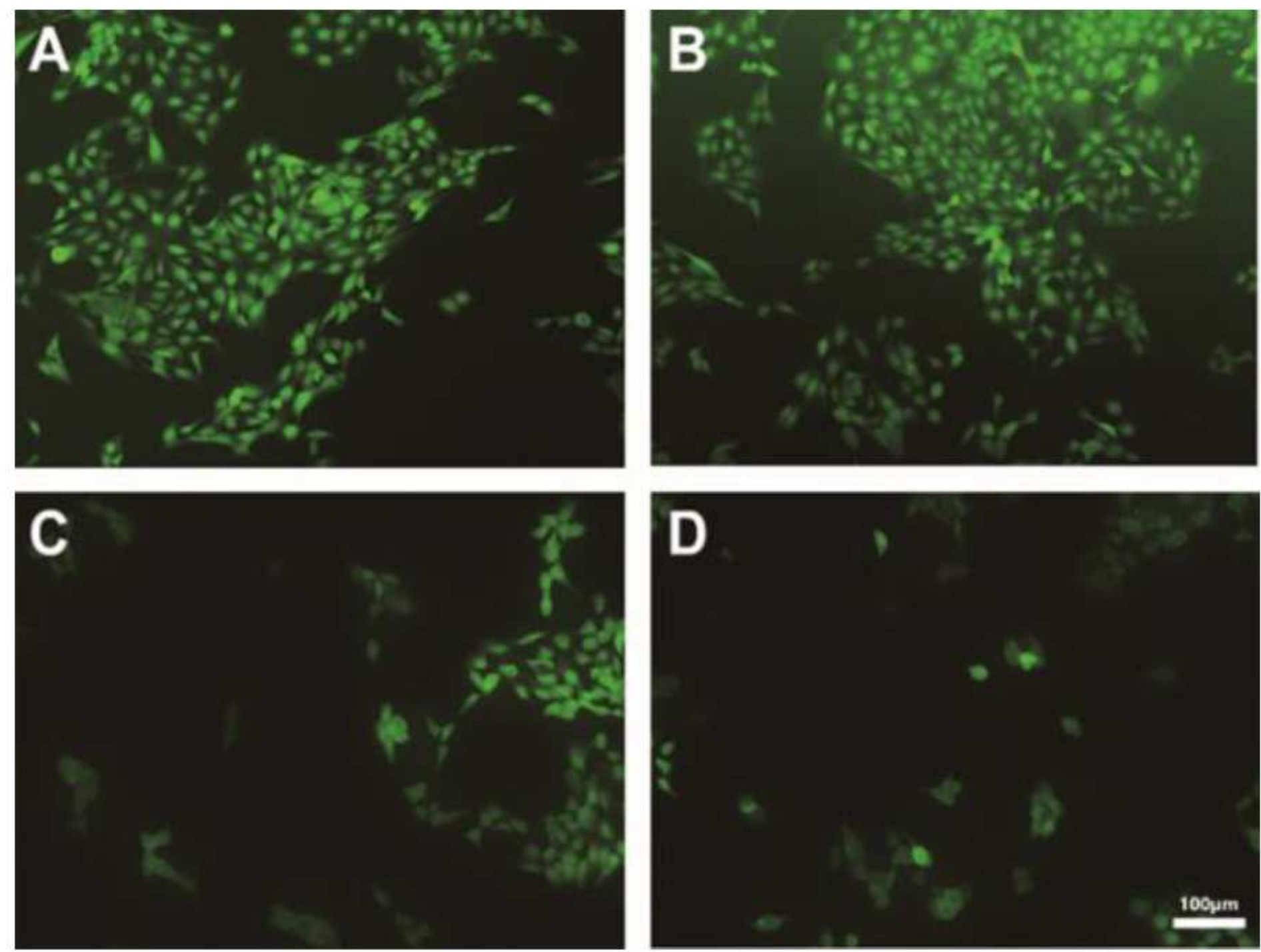

\section{Figure 1}

Fluorescence images of HLEC cells incubated with PMAMA-NH2 G5.0 aqueous solution with concentrations of (A) $5 \mu \mathrm{g} / \mathrm{mL}$, (B) $25 \mu \mathrm{g} / \mathrm{mL}$, (C) $50 \mu \mathrm{g} / \mathrm{mL}$, and (D) $100 \mu \mathrm{g} / \mathrm{mL}$ overnight after FDA staining for 15 mins. 


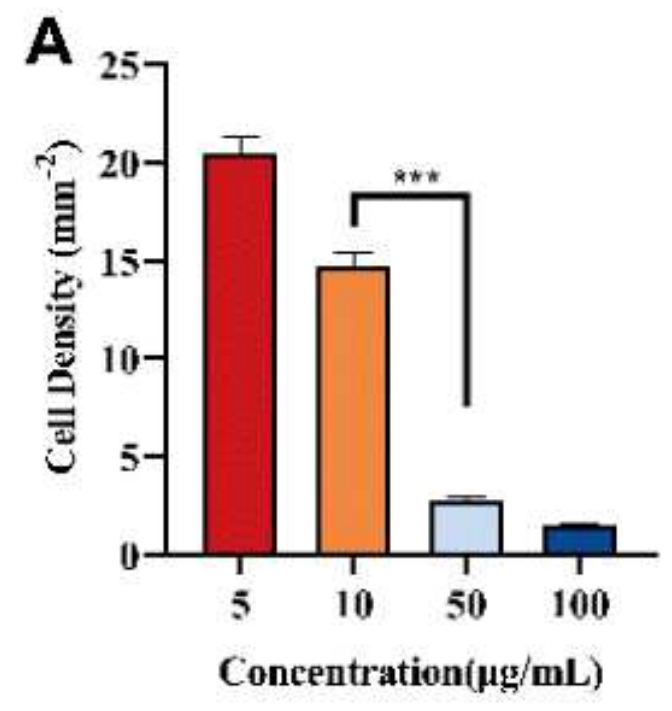

Concentration $(\mu \mathrm{g} / \mathrm{mL})$
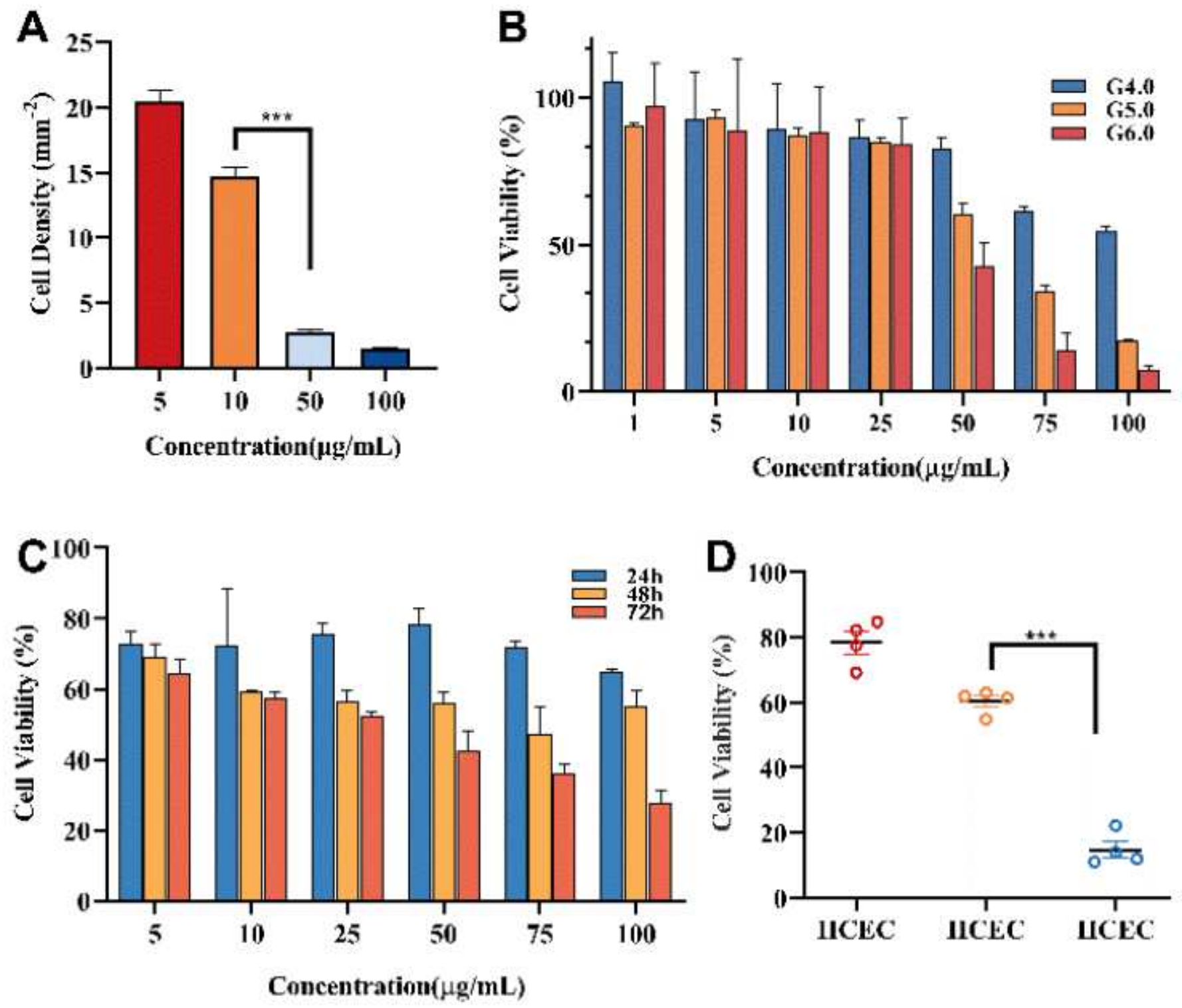

Figure 2

Concentration and generation dependent cell viability of PAMAM incubated with HCECs, HLECs, and RPEs. (A)HLECs density after PAMAM G5.0 treatment overnight. (B) The cell viability of different generations and concentrations of PAMAM incubated with HLECs. (C) Time-dependent cell viability of PAMAM G4.0 incubated with HCECs. (D) The cell viability of PAMAM G5.0 in different ocular cells when the concentration is $50 \mu \mathrm{g} / \mathrm{mL}$. 

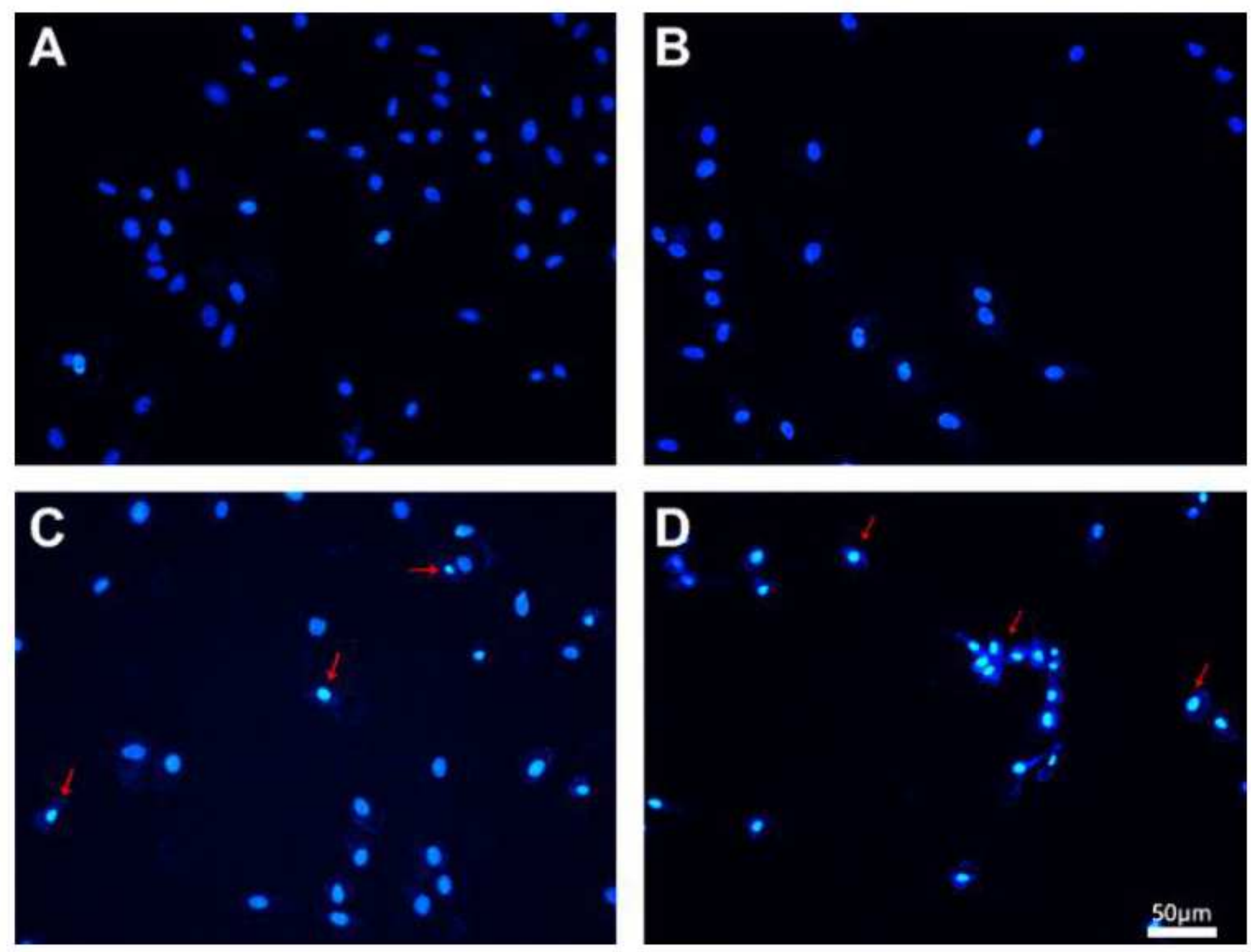

\section{Figure 3}

Hoechst 33342 stained cell nuclear morphology of RPEs in different concentrations of PAMAM G5.0 solution treatment after 24 hours incubation. PAMAM G5.0 solution: (A) PBS as a control; (B) $25 \mu \mathrm{g} / \mathrm{mL}$; (C) $50 \mu \mathrm{g} / \mathrm{mL}$; and (D) $100 \mu \mathrm{g} / \mathrm{mL}$. 

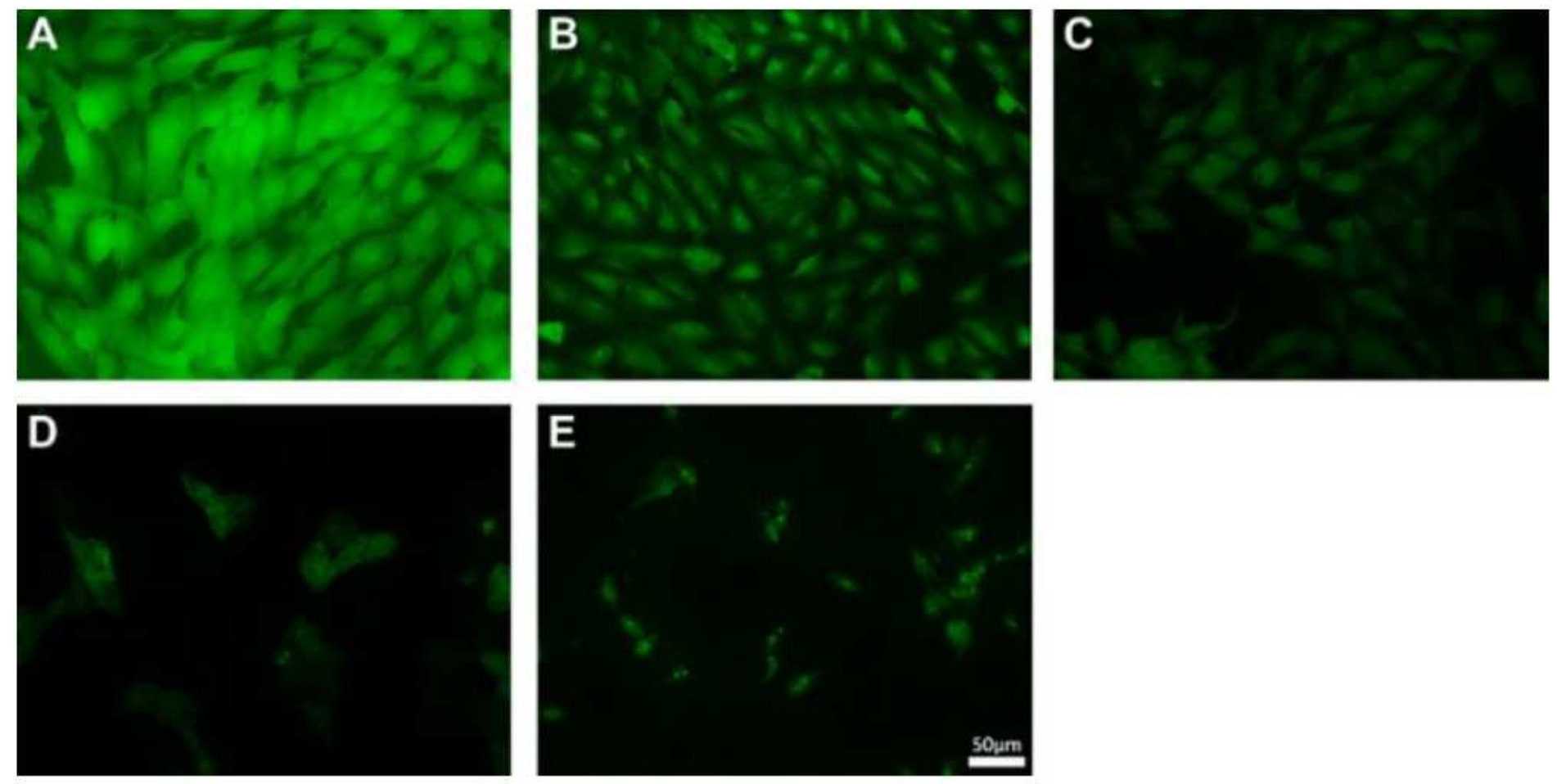

\section{Figure 4}

Singlet oxygen generation and enhanced in vitro cytotoxicity. Fluorescence images of RPEs incubated with PAMAM G5.0 solution (A) Rosup solution as positive control, (B) $5 \mu \mathrm{g} / \mathrm{mL}$, (C) $25 \mu \mathrm{g} / \mathrm{mL}$, (D) 50 $\mu \mathrm{g} / \mathrm{mL}$, (E囚100 $\mu \mathrm{g} / \mathrm{mL}$. 

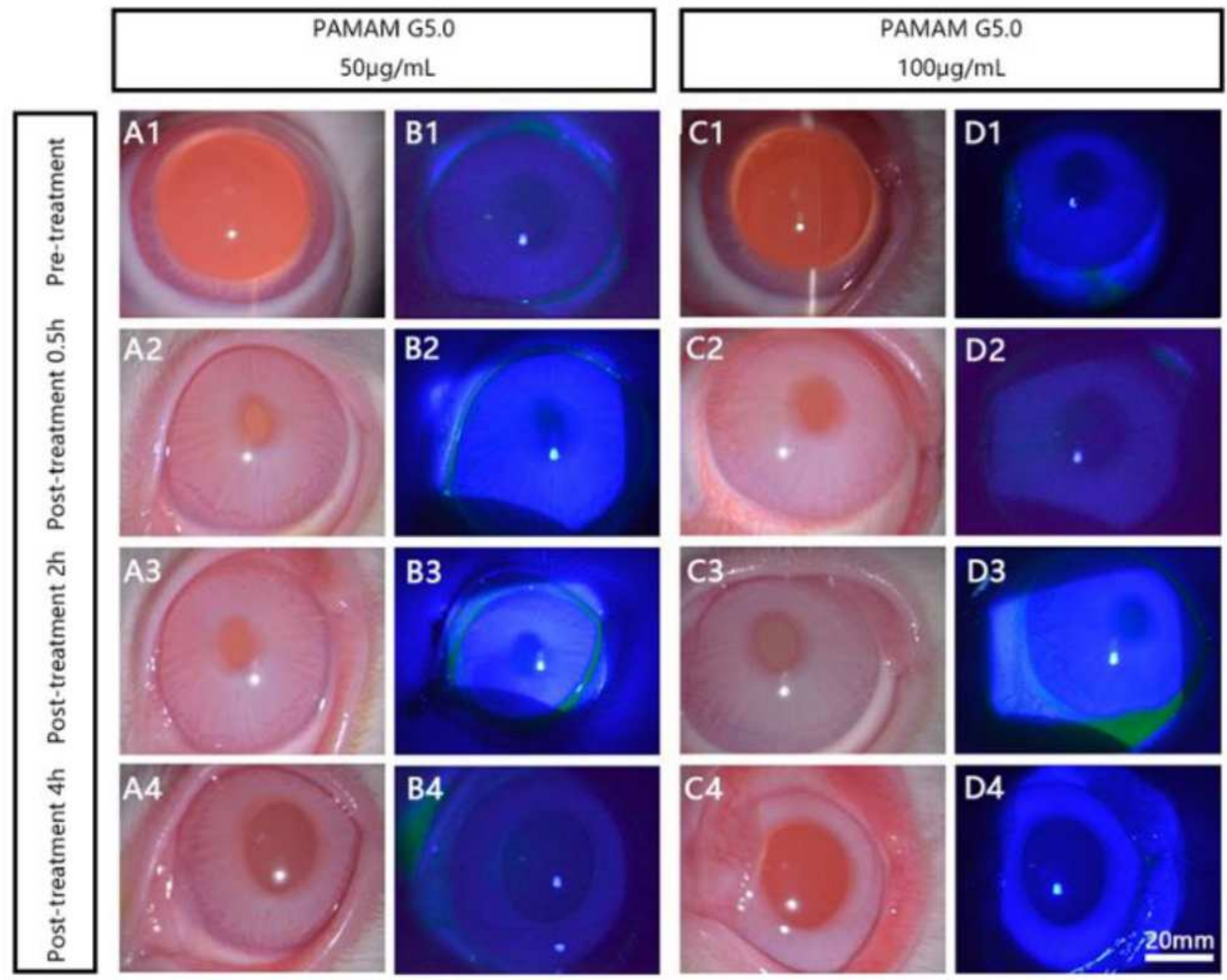

Figure 5

Representative slit-lamp photographs (with or without fluorescein disodium staining) of the rabbit eyes irritated by PAMAM G5.0 at the concentration of $50 \mu \mathrm{g} / \mathrm{mL}$ (A1-A4, B1-B4) and $100 \mu \mathrm{g} / \mathrm{mL}$ (C1-C4, D1-D4) pre-treatment and post-treatment $0.5 \mathrm{~h}, 2 \mathrm{~h}, 4 \mathrm{~h}$. 

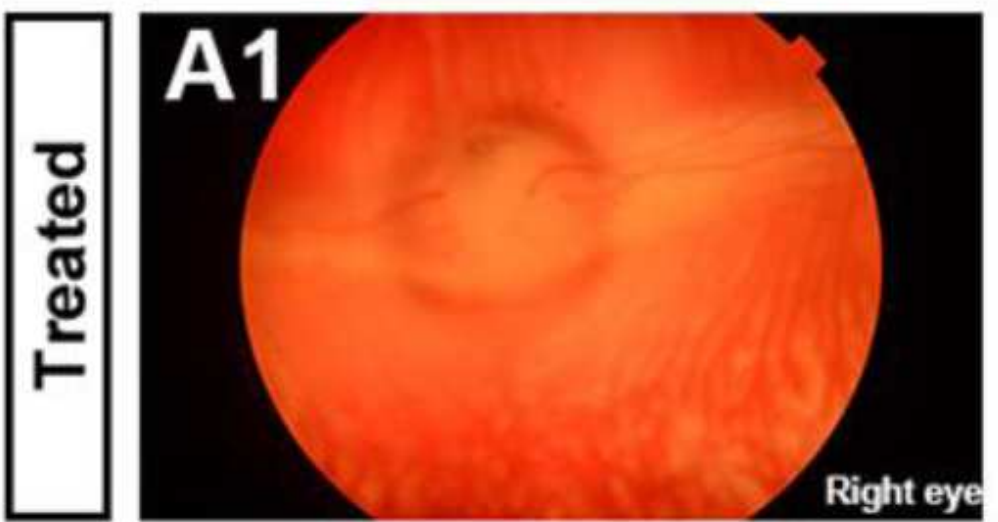

\section{B1}
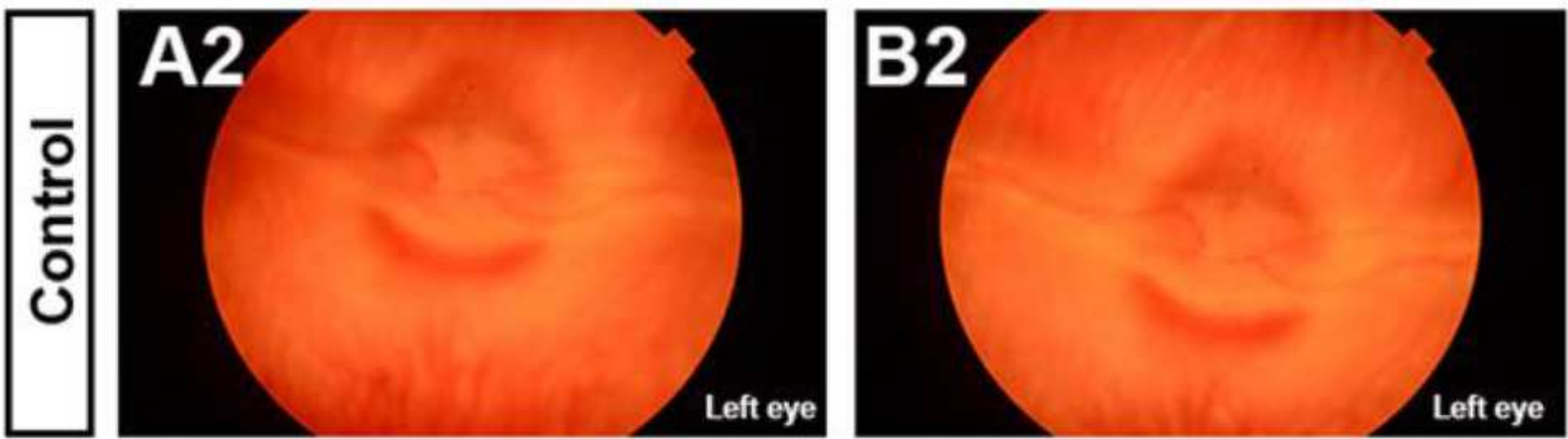

Figure 6

The fundus images of the rabbit eyes after $20 \mu \mathrm{L}$ PAMAM G5.0 intravitreal injection for 7 days at the concentration of $50 \mu \mathrm{g} / \mathrm{mL}(\mathrm{A} 1)$ and $100 \mu \mathrm{g} / \mathrm{mL}$ (B1). The untreated opposite eyes were severed as the negative control (A2 and B2). 

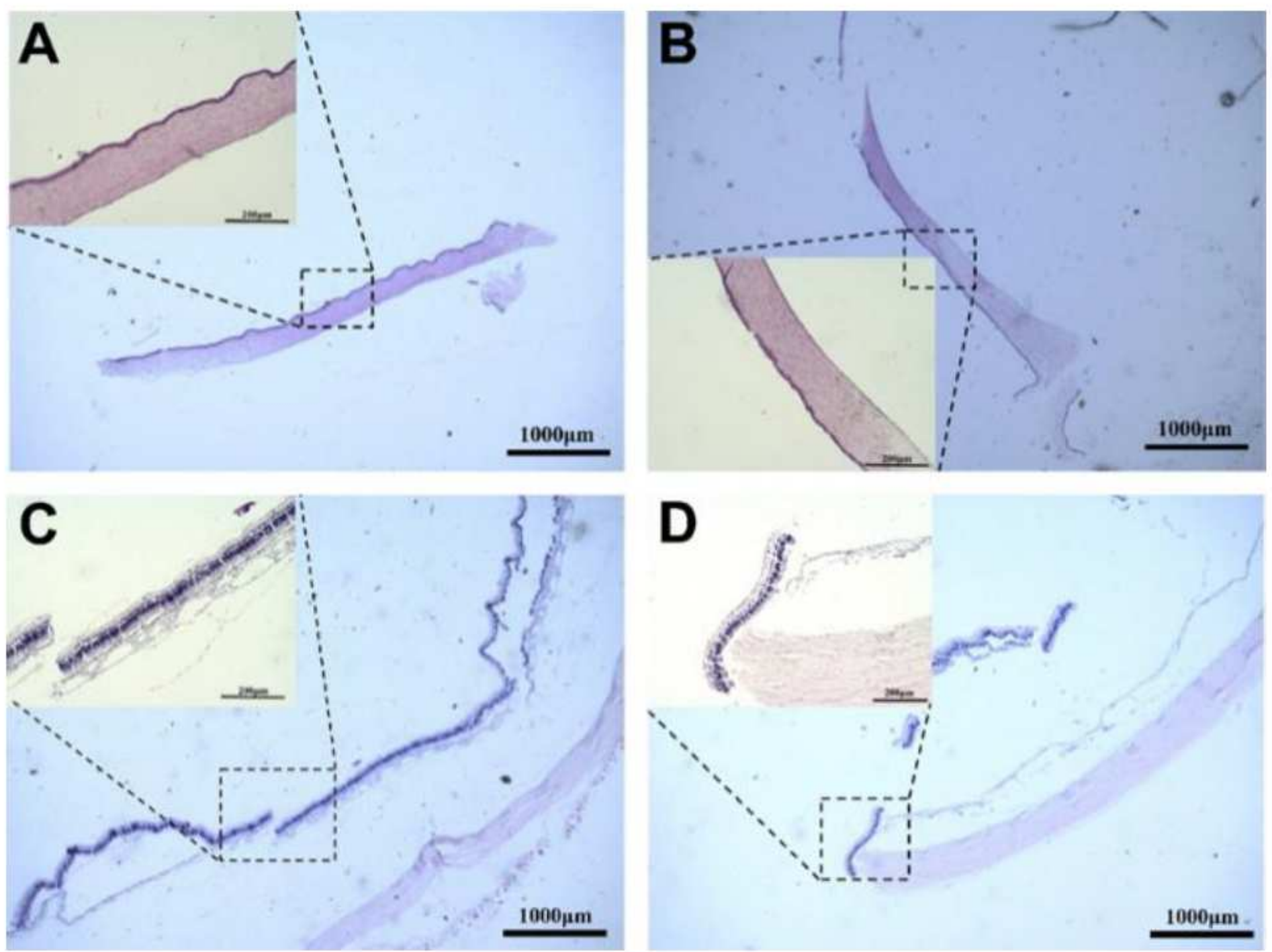

Figure 7

Light photomicrographs of histological section images of the cornea (A, B) and retina (C, D) after 50 $\mu \mathrm{g} / \mathrm{mL}(A$ and $C$ ) and $100 \mu \mathrm{g} / \mathrm{mL}$ (B and D) PAMAM G5.0 intravitreal injection for 7 days. 

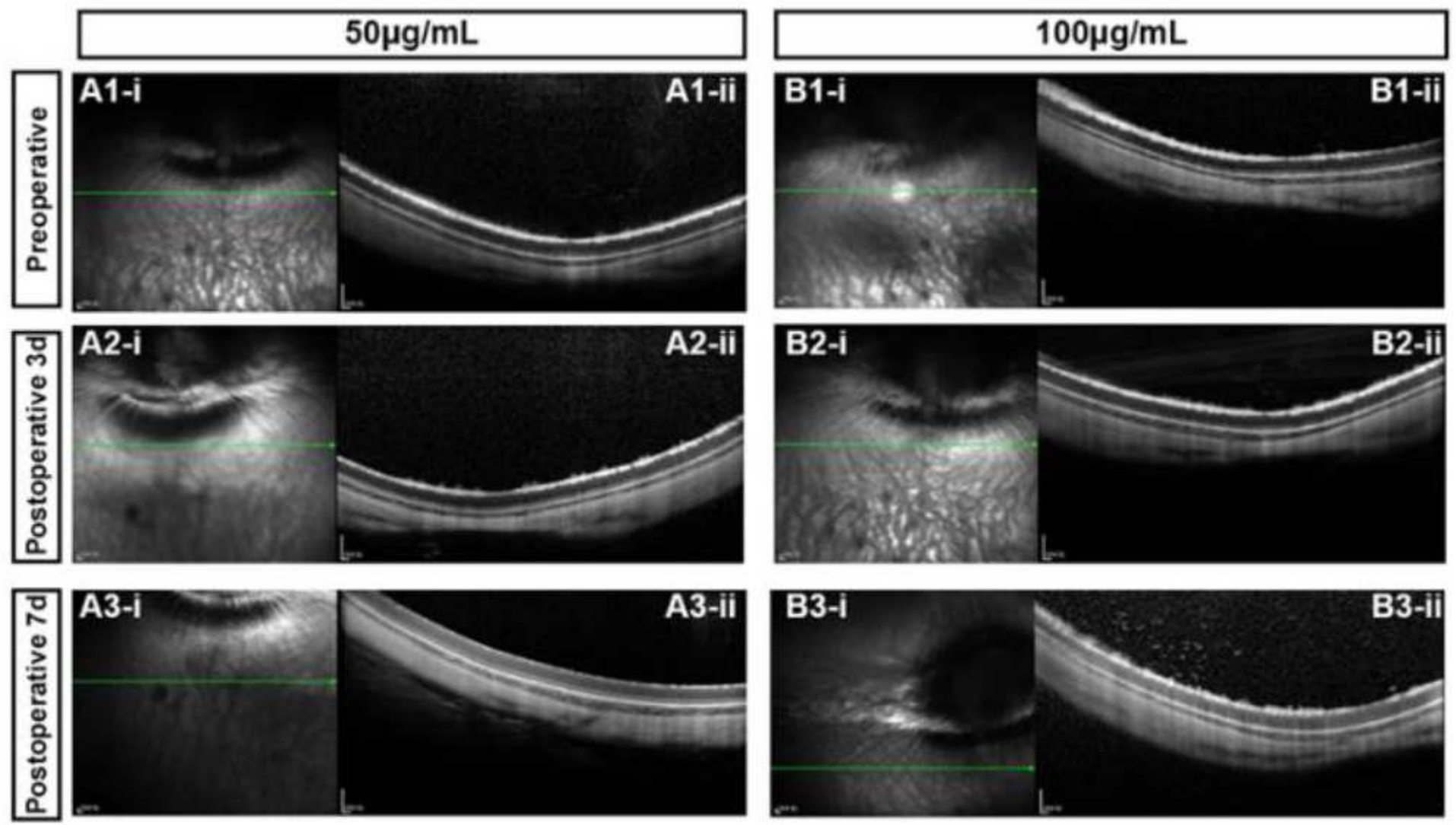

Figure 8

Pre (A1, B1) and postoperative 3 days (A2, B2), 7 days (A3, B3) OCT images of the fundus (A-i, B-i) and its cross-section view (A-ii, B-ii) after $50 \mu \mathrm{g} / \mathrm{mL}(\mathrm{A})$ and $100 \mu \mathrm{g} / \mathrm{mL}$ (B) PAMAM G5.0 intravitreal injection for 1 week. 


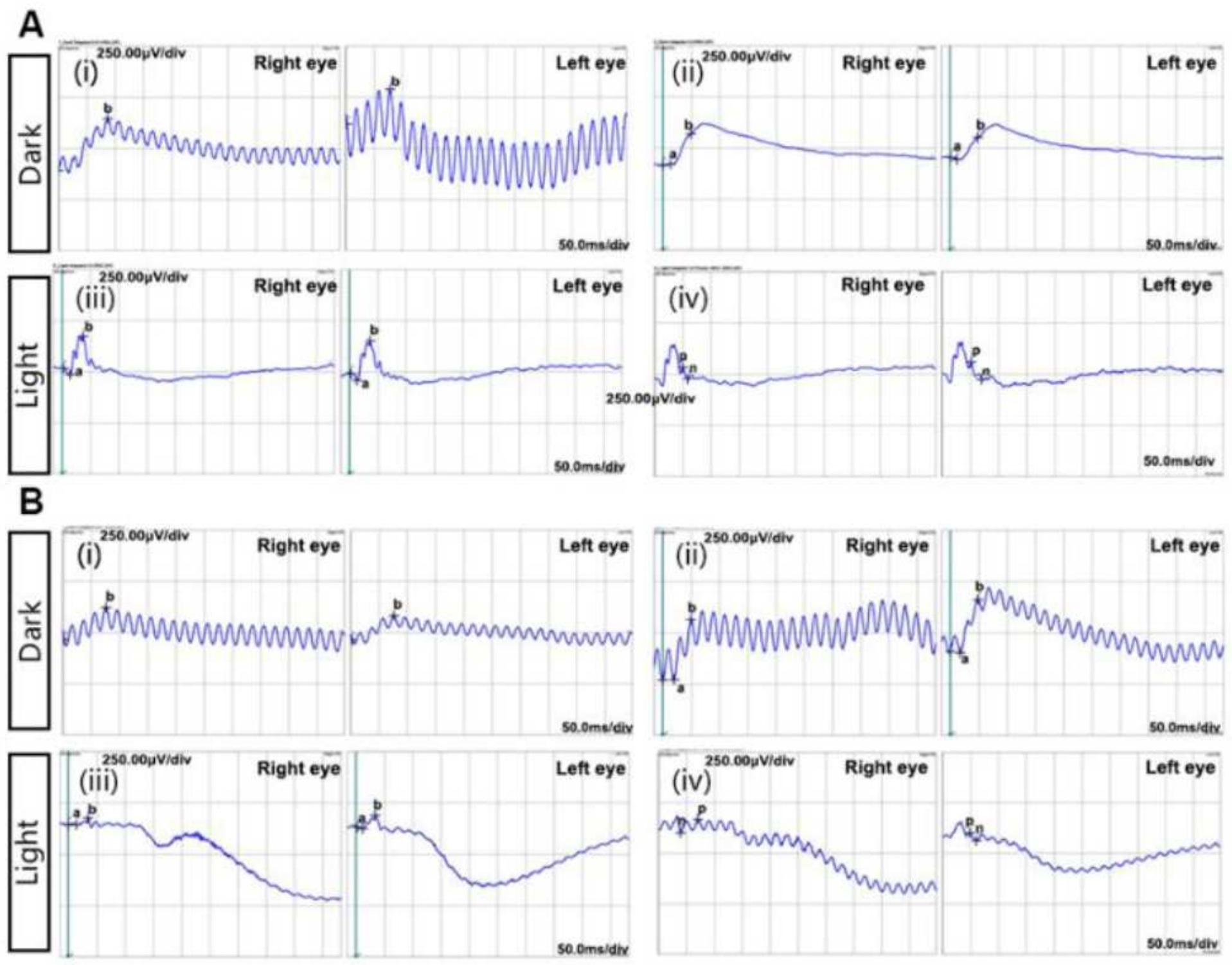

Figure 9

The ERG results of the rabbit eyes after $50 \mu \mathrm{g} / \mathrm{mL}$ (A-right eye) and $100 \mu \mathrm{g} / \mathrm{mL}$ (B-right eye) PAMAM G5.0 intravitreal injection for 7 days. The untreated opposite eyes were severed as the negative control (A-left eye, B-left eye). ERG MODE: Dark Adapted 0.01 ERG (i), Dark Adapted 3.0 ERG (ii), Light Adapted 3.0 ERG (iii), and Light Adapted 3.0 Flicker 30Hz ERG (iv). 